\title{
ANALYSIS OF SOCIO-ECONOMIC SYSTEM PROCESSES PERFORMANCE WITH THE HELP OF EIGENSTATE MODELS
}

V.V. Mokeyev, South Ural State University, Chelyabinsk, Russian Federation, mokeyev@mail.ru, D.A. Vorobiev, South Ural State University, Chelyabinsk, Russian Federation, denis74.chel@mail.ru.

Analysis of the performance of business processes for socio-economic systems is considered. The analysis of the business processes efficiency is based on constructing on of a "perfect image" of their behavior. To extract the components that correspond to the "perfect image" of behavior, we propose the usage of eigenstate method, which allows to represent behavior of socio-economic system as a sum of independent components (eigenstates). The basic relationships of eigenstate method are considered. Construction of the socio-economic system models using the eigenstate method consists in calculation and selection of key eigenstates oriented towards formulated success factors. The selected eigenstates are used to form a "reference" model of the socio-economic system. The high performance of socioeconomic system is evaluated with the help of comparison of model and actual values of socio-economic system variables. The eigenstate method efficiency is demonstrated by the example of analysis of sustainable development of the Chelyabinsk city. The sustainable development indicators of processes of the Chelyabinsk city are obtained.

Keywords: analysis; efficiency; business process; principal component analysis; eigenstate model.

\section{Introduction}

Today, there is a number of approaches for evaluating of the performance of a set of peer entities called Decision-Making Units (DMUs). The definition of a DMU is generic and flexible. DMUs of various forms are used to evaluate the performance of entities, such as hospitals, universities, cities, courts, business firms, countries, regions, etc. The processes of socio-economic systems can be considered as DMU. A socio-economic system means an organization, an enterprise, a region. Socio-economic system continually improves processes to keep them competitive. Analysis of DMU to be improved will be a starting point of the improvement process of socio-economic systems. One needs to be aware that on the one hand socio-economic systems are semi-structured systems and are characterized by a lack of high-quality models of the processes occurring within them. Analysis of performance of socio-economic systems is carried out by observing the indicators change that describe DMU and by finding cause-effect relationships between them. The DMU are described by extensive set of indicators, processing of which causes certain difficulties when using traditional methods.

Recent years have seen a great variety of techniques for use in evaluating of the performances of many different kinds of entities engaged in many different activities in many different contexts in many different countries. One of them is the Data Envelopment Analysis (DEA). DEA is a methodology which evaluates the relative efficiency of a set of DMU. In [1] DEA is used to examine the efficient use of different types of enterprise information in the realization of strategic performance. 
The efficiency of Chinese banks' activity in the period between 1997 and 2008 is determined by means of analyzing of the business environment [2]. A new simulation model based on agents to simulate the causes and processes of financial difficulties at an enterprise is described in [3]. The main model structure includes four agents: the company (enterprise), the product, the bank and the macro environment. Exploring various causes of financial difficulties at different stages of the company life cycle the researchers were able to implement their model for the four cases, which are the start, growth, maturity and decline. When the results had been compared with the original data, they concluded that the proposed simulation model is a promising tool for in-depth analysis of the causes and processes of financial instability.

The principal component analysis is another effective approach allowing establishing and measuring the causal relationships between various processes within the socioeconomic systems. One of the important advantages of the method of principal components is that it allows presenting the behavior of the system under investigation as a set of (statistically) independent components, each of which can be analyzed separately.

Principal component analysis combined with DEA is applied in order to solve this issue objectively $[4,5]$. An alternative, non-parametric benchmarking methodology, the free disposal hull [6] does not assume convexity of the frontier as DEA does, hence the number of efficient units grows to such an extent that the results are too weak to reach any conclusions [7].

The development of the principal component method as applied to the analysis and forecasting of socio-economic systems allows us to formulate a new method that can be called the eigenstate method.

Building the models of socio-economic systems using the eigenstate method consists in calculation and selection of key eigenstates oriented towards formulated success factors and clearly demonstrating the cause-and-effect interactions associated with the strategic nature of the company development changes.

\section{Eigenstate Method}

Let the state of a socio-economic system be described by a set of variables $x_{k i}^{0}$, where $i$ is the variable number $(i=1,2,3, \ldots, n), k$ is the economic entity number $(k=1$, $2,3, \ldots, m), n$ is the number of variables, $m$ is the number of states of the economic entities. The values of each variable for the various states of economic entities form a vector $x_{i}^{0}=\left\{x_{1 i}^{0}, x_{2 i}^{0}, \cdots, x_{m i}^{0}\right\}^{T}$.

The space of variables of a socio-economic system can be represented as a matrix of basic variables $\mathbf{X}^{0}$, where each matrix column contains the values of one variable for the various states of the socio-economic system, and each row contains the values of all the variables and describes the state of the economic entity. Thus, the state space of the socio-economic system will be described as follows

$$
\mathbf{X}^{0}=\left[\begin{array}{llll}
x_{1}^{0} & x_{2}^{0} & \cdots & x_{\mathrm{n}}^{0}
\end{array}\right]
$$

The arithmetic mean of variables is used as a center of distribution of the state space. The centered state space will be represented by a matrix $\mathbf{X}$, in which each element is defined as:

$$
x_{k i}=x_{k i}^{0}-\bar{x}_{i}
$$

where $\bar{x}_{i}=\frac{1}{m} \sum_{k=1}^{m} x_{k i}^{0}$. 
The principal components are a group of variables, in which the members of the group (variables) are inter-related, but the group (principal component) as a whole would be independent from the other groups (principal components).

To calculate the weight coefficients of the principal components a eigenvalue problem is solved

$$
(\mathbf{A}-\lambda \mathbf{I}) \mathbf{v}=0,
$$

where $\mathbf{A}$ is a scatter matrix, $\mathbf{I}$ is an identity matrix, $\mathbf{v}$ is an eigenvector of equation (3), $\lambda$ is an eigenvalue. Eigenvectors of equation (3) are scaled so, that $v_{i}^{T} v_{i}=1$ and are orthogonal

$$
\mathbf{V}^{T} \mathbf{A V}=\boldsymbol{\Lambda} \text { and } \mathbf{V}^{T} \mathbf{V}=\mathbf{I}
$$

where $\Lambda$ is a diagonal matrix whose diagonal coefficients are equal to the eigenvalues of the equation (3). The scatter matrix can be computed using matrix of centred variables $\mathbf{A}=1 / m \mathbf{X}^{T} \mathbf{X}$ or matrix of non-centred variables $\mathbf{A}^{0}=1 / m \mathbf{X}^{0^{T}} \mathbf{X}^{0}$.

Each eigenvector has the same size as the state vector of the socio-economic system that allows us to call it an eigenstate. Since the eigenvector is determined with an accuracy up to a multiplier, the eigenstate components show not so much the amount of variables but their relationship with each other.

Thus, the state of socio-economic system at any given time can be described by a weighted combination of eigenstates. At the same time the state of the socio-economic system is described by a set of principal components, but each principal component already reflects not a single variable, but a group of variables (eigenstate of the socio-economic system).

When the eigenvectors are calculated based on the scatter matrix $\mathbf{A}$, the eigenvalues show the variability of the eigenstates in a general state of the socio-economic system and are numerically equal to the dispersion of the principal components.

The eigenstates matrix $\mathbf{V}_{0}$ is formed of the eigenvectors of equation (3) and allows to generate new variables (principal components) as a combination of variables $z_{k i}=$ $\sum_{h=1}^{n} \mathrm{v}_{h i} x_{k h}$, where $z_{k i}$ is the value of the $i$-th new variable for the $k$-th economic entity, $\mathrm{v}_{h i}$ is the element corresponding to the $h$-th variable of the $i$-the new variable. The value $i$ of the principal component for different states of economic entities are combined into a vector $\mathbf{z}_{i}$, forming matrix $\mathbf{Z}$, which is defined as

$$
\mathrm{Z}=\mathrm{XV}
$$

Theorem 1. When describing the state of the socio-economic system as a weighted sum of the eigenstates the principal components are correlatively independent and represent the functions of the eigenstates changing.

Proof. The correlative independence of the principal components means that the scatter matrix of the principal components $\mathbf{Z}$ is a diagonal one.

$$
\mathbf{Z}^{T} \mathbf{Z}=(\mathbf{X V})^{T} \mathbf{X V}=\mathbf{V}^{T} \mathbf{X}^{T} \mathbf{X V}=\mathbf{V}^{T} \mathbf{A V}=\boldsymbol{\Lambda}
$$

Theorem 2. Variables within the framework of each eigenstate can only be changed in proportion to the characteristics of the eigenstate. 
Proof. The process of the socio-economic system state changing is represented as the sum of independent processes, each of which is described by the eigenstate. The change of variables within a single process (eigenstate) cannot impact the change of variables of other processes (eigenstates).

Let the change of variables be described by $\Delta x_{j}(t)=\alpha C$, where $\alpha$ is the vector of variables modification scaled so that $\alpha^{T} \alpha=1$. Then the change of the principal components is described by

$$
\Delta z_{i}(t)=\sum_{k=1}^{n} \Delta x_{k} v_{k i}=C \sum_{k=1}^{n} \alpha_{k} v_{k i}=C\left(\alpha^{T} v_{i}\right) .
$$

Therefore if the change of the $i$-th principal component is described by the variables increment vector $\alpha$ equal to vector of the $i$-the eigenvalue $v_{i}$, then the increment $\left.\Delta z_{i}(t)_{i}\right)$ is equal to

$$
\Delta z_{i}(t)=C v_{i}^{T} v_{i}=C .
$$

In this case the change of other principal components is equal to

$$
\Delta z_{j}(t)=C v_{i}^{T} v_{j}=0 \quad(j \neq i) .
$$

This means that if the object behavior is described by the $i$-th principal component, the baseline variables can only change proportionally to the coefficients of the eigenstate vector $v_{i}$.

The analysis of the eigenstates of a socio-economic system is based on verifying whether the eigenstate satisfies the management requirements of the socio-economic system. Eigenstates that do not satisfy such requirements are discarded, and the eigenstates satisfying the requirements are used to build a socio-economic system reference model.

Let the reference model be formed from $p$ eigenstates. Then the reference model of the socio-economic system is described by the variables that are calculated according to the formula

$$
x_{k i}^{e t}=\bar{x}_{i}+\sum_{h=1}^{p} \mathrm{v}_{h i} z_{k h} .
$$

The contribution of each principal component to the overall variability of the economic object can be evaluated through its dispersion. However, the dispersion of the principal components can only serve as an approximate estimate, as the dispersion of the baseline variables can be significantly different. And it is well known that the baseline variables with the highest dispersion dominate within the first principal components.

\section{Performance Analysis of Socio-Economic Systems}

The performance analysis of socio-economic systems (organizations, companies, regions, etc.) as a network of business processes includes the following steps:

1. Formation of a set of variables to assess the efficiency of a socio-economic system. The set is formed by variables that describe the state of the processes of socio-economic systems. During the analysis, an expert can select the most important variables from this set. 
2. The requirements for the socio-economic system efficiency management are drafted. Simulation always involves assumptions with varying degrees importance that are expedient to be stated taking into account the main goals of development of socio-economic systems.

3. The socio-economic system states are decomposed into sums of independent components (eigenstates ). At this step a scatter matrix is constructed, and eigenstates of the socio-economic system are calculated.

4. Analysis of eigenstates for compliance with efficiency management requirements. The analysis includes verification of the compliance of eigenstates with the requirements of performance management of the socio-economic system, which appear to be some restrictions to the modifications of basic variables. The selected eigenstates are used to form a model of the socio-economic system, which is a "reference" model of socio-economic system as it fully meets the requirements of the performance management.

5. Calculation of indicators to assess whether the behavior of socio-economic system complies with the formulated requirements.

The assessment of the $k$-th indicator compliance with the stated requirements can be defined with the help of the $\gamma$ indicator

$$
\gamma_{\mathrm{i}}=1-\frac{\sum_{k=1}^{m}\left|x_{k i}^{0}-x_{k i}^{e t}\right|}{\sum_{k=1}^{m}\left|x_{k i}^{0}-\bar{x}_{i}\right|} .
$$

The closer is the reference process to the real one the closer is the $\gamma$ indicator value to 1 or to $100 \%$. If a business process is described by $s$ parameters, it is possible to deduce a criterion of the process compliance with the requirements of the system development efficiency

$$
\beta=\frac{1}{s} \sum_{i=1}^{s} \gamma_{i}
$$

\section{Analysis of Sustainable Development of the Chelyabinsk City}

Analysis of the sustainable development of the Chelyabinsk city is considered. Concept of sustainable development involves the implementation of urban development activities to ensure prosperous and safe conditions of life, limitation of negative impacts of economic activity on the environment, and rational use of natural resources for the benefit of present and future generations.

The concept of sustainable development is usually considered in three constituent domains: environmental sustainability, economic sustainability and social sustainability.

1. The economic sustainability implies the optimal use of scarce resources and the use of resource-saving technologies including extraction and processing of raw materials, creation of environmentally friendly products, minimization, recycling and disposal of waste;

2. The social sustainability is focused on people and is aimed to preserve the stability of social and cultural systems;

3. The environmental sustainability implies that sustainable development should ensure the integrity of biological and physical natural systems. 
The main focus is made on preserving of the abilities to self-recovery and dynamic adaptation of such systems to changes, rather than on keeping them in some "ideal" static state. Degradation of natural resources, pollution of the environment and loss of biological diversity reduce the ability of ecosystems to self-recovery.

Socio-economic development of the Chelyabinsk city is represented as a set of DMU: budget management, entrepreneurship and investment, housing management, demography and employment, environmental protection, transportation and communication control, health and education control, living standards.

In accordance to the concept of sustainable development of the city population growth must be accompanied by improvements in business activities, environment and living standards. Based on these conditions the eigenstates obtained from processing data for 12 years (from 2000 to 2011) are analyzed. The 79 variables used to calculate the eigenstates were selected from the total list of 512 variables. As shown above, changes of variables within each eigenstate may occur only in proportion to the weight coefficients of such eigenstate. Table 1 shows four eigenstates accumulating $99,8 \%$ of the total variables dispersion.

Table 1

Structure of eigenstates

\begin{tabular}{|l|l|l|l|l|}
\hline Indicator name & \multicolumn{4}{l|}{ Eigenstate number } \\
\hline & 1 & 2 & 3 & 4 \\
\hline Population, people & 0,019540 & 0,643900 & 0,039180 & 0,483800 \\
\hline Crude birth rate & 0,000007 & 0,000015 & 0,000000 & $-0,000034$ \\
\hline Crude death rate & $-0,000005$ & $-0,000013$ & 0,000026 & $-0,000021$ \\
\hline $\begin{array}{l}\text { Volume of goods shipped, bln } \\
\text { rubles }\end{array}$ & 0,000493 & 0,000048 & 0,004009 & $-0,000693$ \\
\hline $\begin{array}{l}\text { Electricity production, million } \\
\text { kW/hour }\end{array}$ & 0,005135 & 0,009461 & 0,033210 & $-0,008608$ \\
\hline $\begin{array}{l}\text { Investments to capital assets, } \\
\text { mln rubles }\end{array}$ & 0,134600 & 0,026210 & 0,811700 & 0,193600 \\
\hline Catering turnover, mln rubles & 0,024590 & 0,009005 & $-0,069850$ & 0,040370 \\
\hline $\begin{array}{l}\text { Emissions of pollutants into the } \\
\text { atmosphere, thousand tons }\end{array}$ & $-0,000009$ & $-0,000206$ & 0,001246 & $-0,001167$ \\
\hline $\begin{array}{l}\text { Wastewater discharge, million } \\
\text { cubic meters/year }\end{array}$ & $-0,000212$ & $-0,000477$ & $-0,000201$ & 0,001010 \\
\hline $\begin{array}{l}\text { City housing space, thousand } \\
\text { square meters }\end{array}$ & 0,012730 & 0,023070 & 0,004069 & $-0,019820$ \\
\hline $\begin{array}{l}\text { Average housing space per } \\
\text { person, sq. m. }\end{array}$ & 0,000011 & 0,000007 & 0,000000 & $-0,000028$ \\
\hline Average monthly wages, rubles & 0,035470 & 0,007123 & 0,082320 & $-0,101800$ \\
\hline
\end{tabular}

The analysis of the eigenstates presented in Table 1 shows that population growth leads to an increase in the birth rate and decrease of the death rate coefficient only in the first and second eigenstates. In the first eigenstate as population grows the variables of entrepreneurial activity process also grow (volume of shipped goods, electricity production, 
investments in fixed assets, investments in housing construction, retail trade, public catering turnover, the volume of paid services), variables of environmental protection process improve (emissions of air pollutants and wastewater discharge decrease) as well as the living standard (minimum living wage increases, as well as the average amount of pension and monthly salary).

As a result of the eigenstates analysis a model of sustainable development of the Chelyabinsk city is formed. In this model deviations from the mean values of variables are described by a weighted sum of the first and second eigenstates. It should be borne in mind that the model of sustainable development of the Chelyabinsk city is an idealization of the real process of city development, some perfect way of its development, which corresponds to the concept of sustainable development. However, varying some variables obtained by sustainable development model of the Chelyabinsk city can describe the negative trends existing within the socio-economic system of the city that do not correspond to the concept of sustainable city development. Variables describing the demographic and employment process are generally well described by a model of sustainable development of the Chelyabinsk city. The discrepancy between the model and actual values of variables is generally less than 5\%. Variables describing population migration and unemployment are an exception.

According to the analysis of dynamics of entrepreneurship and investment processes, we can make a conclusion that they also correspond to the model of sustainable development of the Chelyabinsk city quite well. The average discrepancy between the actual and the model values does not exceed $10 \%$, although the maximum discrepancy can reach up to $30 \%$ for the variables describing catering and paid services. As an example Fig. 1 shows a diagram of changes in the volume of electricity production. Actual values are indicated by a solid line, and the values of obtained with the sustainable development model of the Chelyabinsk city are indicated by a dotted line.

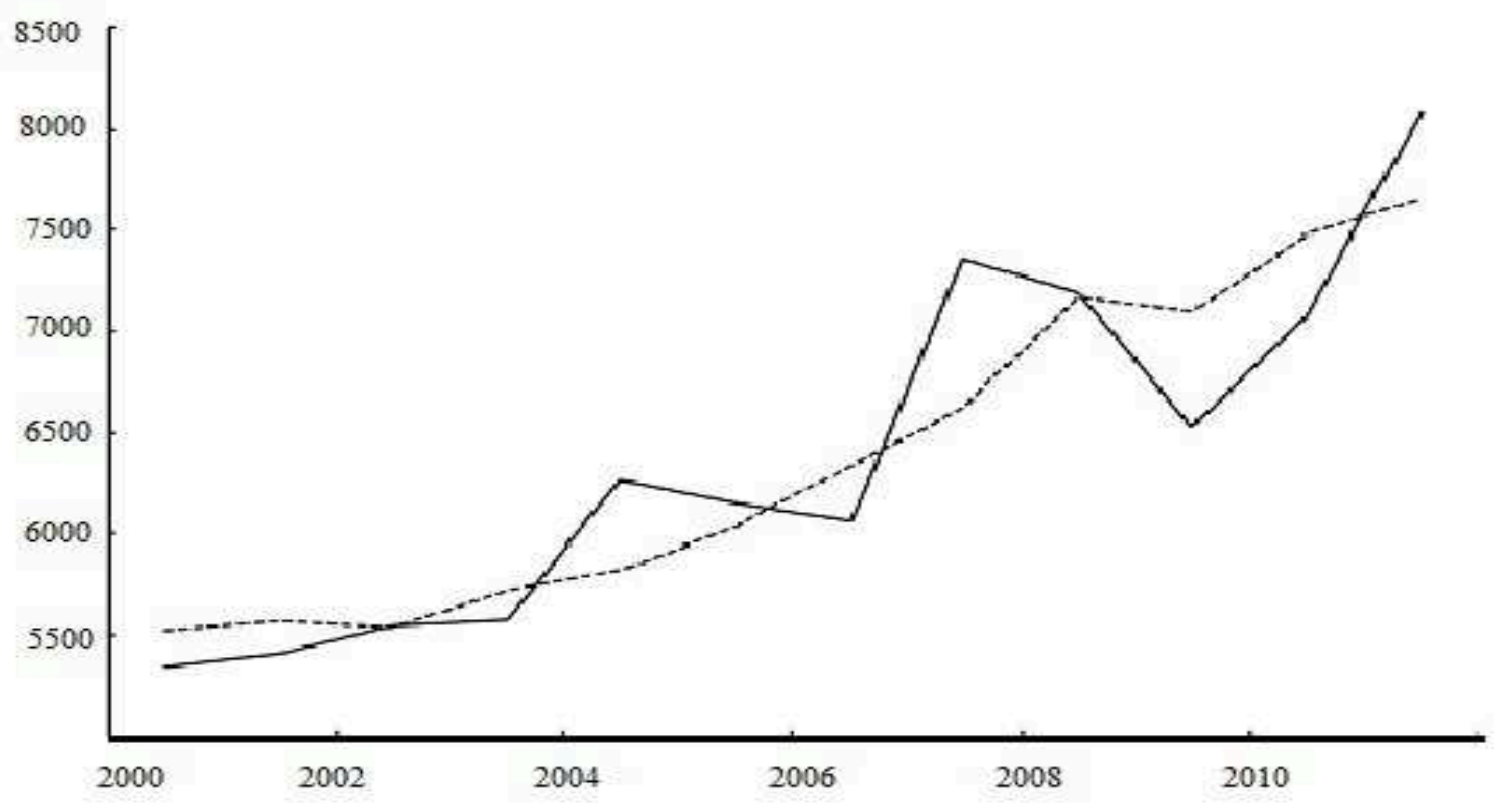

Fig. 1. Electricity production volume 
The average deviation of discrepancies between the actual and the model values of electricity output amounts 3,9\%, and the maximum discrepancy is $9,9 \%$. In general the actual change of electricity production volume corresponds well to the sustainable development model of the Chelyabinsk city.

For the environment protection process the average discrepancy between the actual and the model values of variables does not exceed 10\%, although the maximum discrepancy for the variables describing garbage disposal and landscaped areas reaches $40 \%$. Fig. 2 shows a diagram of changes of emissions of air pollutants into the atmosphere. Actual values are indicated by a solid line, and the values of variables obtained by the sustainable development model of the Chelyabinsk city are indicated by a dotted line. The figure shows that the volume of emissions according to the model of sustainable development of the Chelyabinsk city starts to decline only during 2008-2011 years. Changes of volume of actual emission of pollutants show the ups and downs of heavy industry in the Chelyabinsk city. From the viewpoint of the concept of sustainable development such ups and downs should not lead to abrupt changes of pollutant emissions volumes. Therefore the total city development process has inefficiency features from the viewpoint of the sustainable development concept in terms of the emissions of air pollutants into the atmosphere and of other variables describing the environmental protection process.

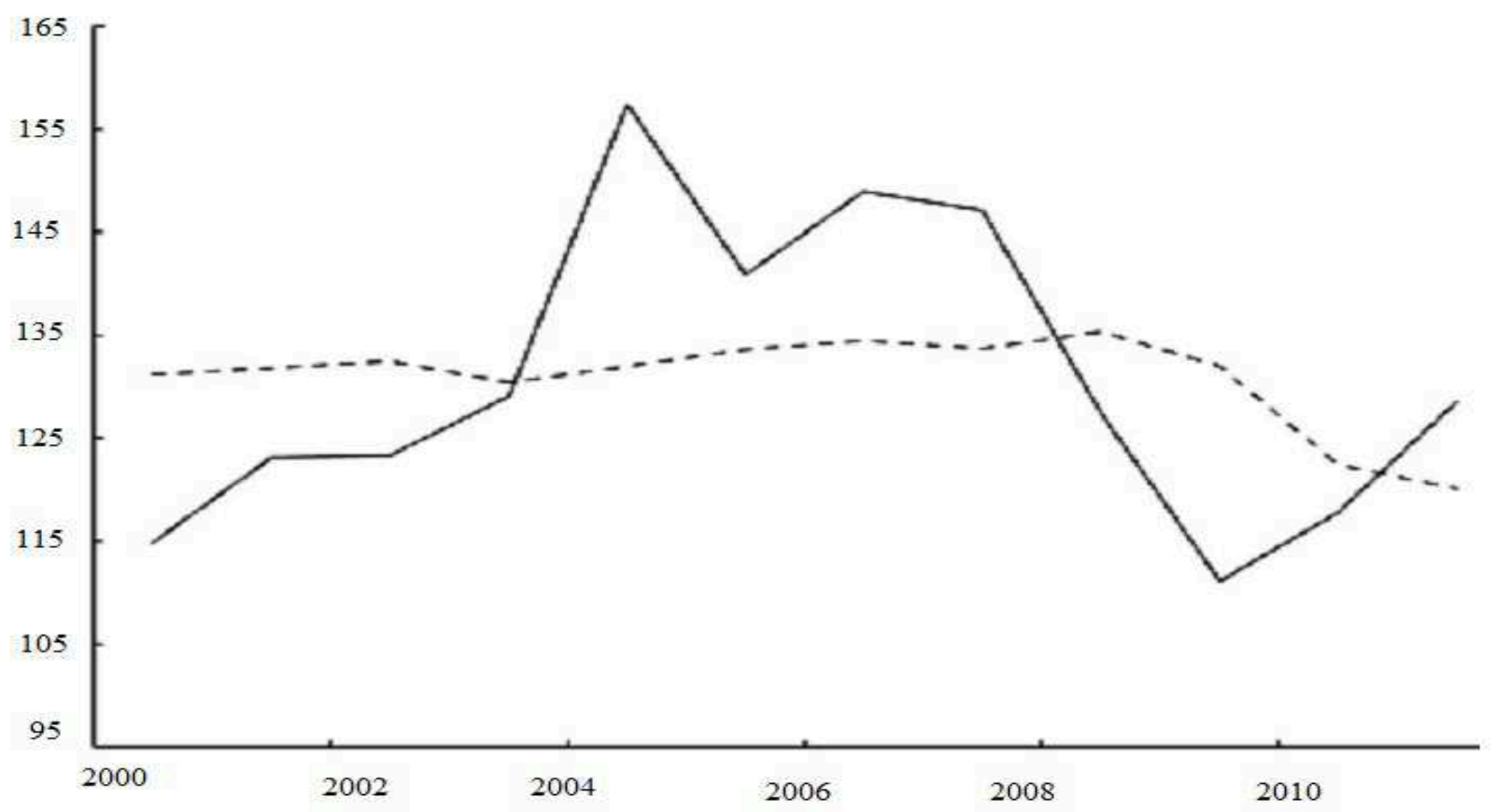

Fig. 2. Emissions of air pollutants into the atmosphere

The process describing the living standard is characterized by the maximum deviation of the actual value of variables (the number of people needed social protection, the number of people registered at the institutions of social protection) from the values obtained by sustainable development model of the Chelyabinsk city. Other processes have the largest discrepancies between the actual and model values for the variables that describe slum dwellings, the number of health care facilities, the number of passengers carried by the municipal transport. Table 2 shows the results of evaluation of compatibility of actual the Chelyabinsk city processes with the sustainable development model. 
Table 2

Evaluation of the DMU compliance with the requirements of sustainable development

\begin{tabular}{|l|l|}
\hline DMUname & $\beta, \%$ \\
\hline Budget management & 82,74 \\
\hline Entrepreneurship and investments & 94,42 \\
\hline Apartment house management & 83,00 \\
\hline Demography and employment & 84,91 \\
\hline Environmental protection & 68,08 \\
\hline Transport control and communication control & 93,06 \\
\hline Health and education control & 91,90 \\
\hline Living standards & 81,92 \\
\hline
\end{tabular}

The table 2 shows that the processes of entrepreneurship and investments have to best correspondence to the concept of sustainable development, while the process of environmental protection complies the worst.

\section{Conclusions}

Analyses of socio-economic systems has been performed. The eigenstate method was used to solve the problem. Main relations of the eigenstate method were presented. The eigenstate method was used for building "reference" models of socio-economic systems. The possibility of usage of this method has been demonstrated by the analysis of socioeconomic development of the Chelyabinsk city in terms of the concept of sustainable development. The sustainable development indicators of processes of the Chelyabinsk city have been calculated.

Acknowledgements. This research is supported by the grant No 14-01-00054 from RFBR (Russian Foundation Basic Research). The authors thank RFBR for the support.

\section{References / Литература}

1. Elliot Bendoly, Eve D. Rosenzweig, Jeff K. Stratman. The Efficient Use of Enterprise Information for Strategic Advantage: A Data Envelopment Analysis. Journal of Operations Management, 2009, vol. 27, issue 4, pp. 310-323. DOI: 10.1016/j.jom.2008.11.001

2. Mette Asmilda, Kent Matthews. Multi-Directional Efficiency Analysis of Efficiency Patterns in Chinese Banks. European Journal of Operational Research, 2012, vol. 219, issue 2, pp. 434-441. DOI: 10.1016/j.ejor.2012.01.001

3. Yu Cao, Xiao-hong Chen. An Agent-Based Simulation Model of Enterprises Financial Distress for the Enterprise of Different Life Cycle Stage. Simulation Modelling Practice and Theory, 2012, vol. 20, issue 1, pp. 70-88. DOI: 10.1016/j.simpat.2011.08.008

4. Adler N., Golany B. Evaluation of Deregulated Airline Networks Using Data Envelopment Analysis Combined with Principal Component Analysis with an Application to Western Europe. European Journal of Operational Research, 2001, vol. 132, issue 2, pp. 260-273. DOI: 10.1016/S0377-2217(00)00150-8

5. Adler N., Yazhemsky E. Improving Discrimination in Data Envelopment Analysis: PCA-DEA or Variable Reduction. European Journal of Operational Research, 2010, vol. 202, issue 1, pp. 273-284. DOI: 10.1016/j.ejor.2009.03.050 
6. Tulkens H. On FDH Efficiency Analysis: Some Methodological Issues and Applications to Retail Banking, Courts and Urban Transport. Journal of Productivity Analysis, 1993, vol. 4, issue 1-2, pp. 183-210. DOI: 10.1007/BF01073473

7. Athanassopoulos A.D., Storbeck J.E. Non-Parametric Models for Spatial Efficiency. Journal of Productivity Analysis, 1995, vol. 6, issue 3, pp. 225-45. DOI: 10.1007/BF01076977

Received November 24, 2014

УДК 62-51

DOI: $10.14529 / \mathrm{mmp} 150105$

\title{
АНАЛИЗ ЭФФЕКТИВНОСТИ ПРОЦЕССОВ СОЦИАЛЬНО-ЭКОНОМИЧЕСКИХ СИСТЕМ С ПОМОЩЬЮ МОДЕЛЕЙ СОБСТВЕННЫХ СОСТОЯНИЙ
}

\author{
В.В. Мокеев, Д.А. Воробъев
}

Рассматривается задача анализа эффективности бизнес-процессов социальноэкономических систем. Анализ эффективности бизнес-процессов базируется на построении «совершенного образа» их поведения. Для выделения состояний, которые соответствуют «совершенному образу» поведения, предлагается использовать метод собственных состояний, который позволяет представить поведение социально-экономической системы в виде суммы независимых компонент (собственных состояний). Рассматриваются основные соотношения метода собственных состояний. Построение моделей социально-экономических систем с использованием метода собственных состояний состоит в вычислении и выборе ключевых состояний, ориентированных на сформулированные факторы успеха. Выбранные собственные состояния используются для построения «эталонной» модели социально-экономической системы. Эффективность социально-экономической системы оценивается путем сравнения модельных и фактических значений показателей социально-экономической системы. Эффективность метода собственных состояний демонстрируется на примере анализа устойчивости развития города Челябинска.

Ключевые слова: анализ; эффективность; бизнес-прочесс; анализ главных компонент; метод собственных состояний.

Владимир Викторович Мокеев доктор технических наук, заведующий кафедрой «Информационные системы», Южно-Уральский государственный университет (г. Челябинск, Российская Федерация), mokeyev@mail.ru.

Денис Анатольевич Воробьев, аспирант кафедры «Информационные системы», Южно-Уральский государственный университет, (г. Челябинск, Российская Федерация), denis74.chel@mail.ru.

Поступила в редакиию 24 ноября 2014 г. 